Article

\title{
Teaching Sustainable Responsibility through Informal Undergraduate Design Education
}

\author{
Louise R. Manfredi $^{1, *}$, Meriel Stokoe ${ }^{2}$, Rebecca Kelly ${ }^{1}$ and Seyeon Lee ${ }^{1}$ \\ 1 School of Design, Syracuse University, Syracuse, NY 13244, USA; rdkelly@syr.edu (R.K.); slee80@syr.edu (S.L.) \\ 2 Arts Administration, Le Moyne College, Syracuse, NY 13214, USA; merielstokoe71@gmail.com \\ * Correspondence: 1rmanfre@syr.edu
}

Citation: Manfredi, L.R.; Stokoe, M.; Kelly, R.; Lee, S. Teaching Sustainable Responsibility through Informal Undergraduate Design Education. Sustainability 2021, 13, 8378. https:// doi.org/10.3390/su13158378

Academic Editor: Grigorios L. Kyriakopoulos

Received: 30 June 2021

Accepted: 23 July 2021

Published: 27 July 2021

Publisher's Note: MDPI stays neutral with regard to jurisdictional claims in published maps and institutional affiliations.

Copyright: (c) 2021 by the authors. Licensee MDPI, Basel, Switzerland. This article is an open access article distributed under the terms and conditions of the Creative Commons Attribution (CC BY) license (https:/ / creativecommons.org/licenses/by/ $4.0 /)$.

\begin{abstract}
Recent reports, initiatives, and activities around higher education institutions revealed the relevance and value of sustainability education through both formal curriculum and informal curriculum activities. While the significance of sustainability education has continuously improved by raising awareness among new generations of students, it has not adequately promoted proenvironmental behaviors or attitude changes. This research study used a linear pretest-posttest experimental approach to understand whether two codesigned interventions; a trash and recycling bin system, and a Materials Exchange program, could improve sustainability literacy and material conservation behaviors across the School of Design. Additionally, a mid-experiment focus group study was conducted to provide text-rich data for analysis of 3R behaviors. Analysis of the data collected revealed that these interventions were reasonably successful in improving responsible material management. To have a greater impact on sustainable behavior, it is suggested that a formal educational experience should supplement the informal interventions described in this paper to onboard students as they enter the design studio culture. Additionally, the expansion of the trash and recycling bin station system into the university dormitories is discussed. This work has successfully catalyzed a collaboration between all School of Design stakeholders to address studio waste in a tangible way.
\end{abstract}

Keywords: studio waste management; design education; sustainable material reuse; reduction; recycling; 3Rs

\section{Introduction}

UNESCO's framework of Education for Sustainable Development 2030 aims to provide the knowledge, awareness, and action that empower people to transform themselves and transform societies through education [1]. Similarly, the United Nations has promoted the importance of integrating their Sustainability Development Goals agenda into higher education to enhance sustainability literacy for students [2]. Such efforts affirm the significance of sustainable development in higher education. A recent report by the International Association of Universities (IAU) entitled “The 2nd Global Survey Report on Higher Education and Research for Sustainable Development" comprehended that sustainability programs at colleges and universities provide an excellent opportunity to raise awareness of the environmental impacts of our daily actions. Thus, college students can and should be convened in response to their environmentally harmful daily practices [3].

Recent reports, initiatives, and activities around the higher education institutions revealed the relevance and value of sustainability education through both formal curriculum and informal curriculum activities [1,4]. Formal sustainability curriculum focuses on scientific knowledge and sensitivity to the environment as integrated into higher education institute (HEI) policy and processes and HEI are used solely as a resource for learning [5]. There are linkages to other sustainable development agendas through this transfer of knowledge; however, there is a question as to whether the formal education 
approach brings a transformative shift. One of the key reflections of UNESCO's ESD 2030 report stated that exposing learners to the reality of sustainability through an informal curriculum would provide opportunities for them to experience how they can influence societal transformation [1]. HEI campuses can be used as a place where "hands-on" practice promotes social change in sustainability [5]. Informal sustainability curriculum such as extra-curricular activities, or participating in faculty research, enhance sustainability literacy and bring about culture change through developing the self-reflecting ability $[6,7]$.

HEIs recognize advancing sustainability as an institutional goal, especially the responsibility in embedding formal and informal educational opportunities [5]. During the 2011 UNESCO's Chair Conference in Higher Education for Sustainable Development, the roundtable discussion identified the key stakeholders in both on and off campus sustainability participation. To make cultural and behavioral shifts in sustainability, students, faculty, administrative leaders, and staff at both institutional and departmental levels must be engaged in the process to bring about change at all levels, including the involvement of the local community in which universities are situated $[4,5]$.

While the significance of sustainability education has continuously improved by raising awareness among new generations of students, it has not adequately promoted pro-environmental behaviors or attitude changes [8]. This is evident in design education specifically, where methodologies in design for sustainability should permeate the full design process, and yet are often lacking in other studio habits [7]. Further, Lee and Manfredi [7] posit that there is a disconnect between creating a sustainable design for production and the initial product development. For sustainable habits to develop in design studio culture, a common understanding of what it means to be sustainable should be agreed upon, and a transformation of how we use and manage materials must occur.

The United Nations defines sustainability as "development that meets the needs of the present without compromising the ability of future generations to meet their own needs" [9]. Defining sustainability becomes more challenging in design, due to variances in the specific types of design one is referencing, in the case of this study: industrial, graphic, environmental, and fashion. A common and universal interpretation that satisfies all fields is required. While explored across various domains, teaching sustainability methodologies involves a multitude of tactics, in and outside the classroom whilst creating simple and repeated opportunities to practice [10]. To increase the potential for success, a critical assessment of learning behaviors and change theory is required. Change theory is the anticipatory belief between desired changes and the actions that may produce those changes [11], and the relationship between the school and its environmental culture through an educational lens [12]. It is important to note that education and cultural norms (in this case, the students' mindset) have the ability to influence the school as well as the school influencing these desired norms [13]. These relationships from student to school and school to student, with a diversified combination of norms, help to establish a multifaceted sustainability mindset (or change) from different directions. Meaning that to make an effective and lasting mindset change, it must be mutually experienced and not a top-down institutional policy only. Layering these interpretations is important in order to have a longterm, practiced, iterative, and repeated sustainability mindset rather than creating reform through one-time interventions [14]. Education and behavioral patterns (in this case, the students' mindset) can influence the school's cultural attitude towards sustainability [13].

Many universities have identified waste management activities as a starting point for their campus sustainability initiatives with varying approaches but similar positive outcomes [15-18]. Consistent messaging and bin designs have contributed to changing waste disposal behaviors [18], although errors are still made if there is no explicit direction for how to dispose of or recycle, specific items. Beyond installing recycling mindfulness on university campuses, design education strategies such as design for re/upcycling, repair and reuse, disassembly, and refurbishment and remanufacture, are emerging in conversations in the design studios. 
The circular economy (CE) approach to design [19] is central to reimagining the lifecycle of products. This approach is key to eliminating waste from the use and consumption of materials $[20,21]$ and by transitioning from a linear use-dispose model to a use-use model, technical materials could theoretically be infinitely cycled through different uses. With respect to studio waste, a similar approach could be modeled whereby students are encouraged to rethink the end-of-life of their prototyping supplies and cascade materials into a new lifecycle, such as a new project of their own or by donating to their peers.

Building upon the success of the pilot study in the School of Design [7], this research aimed to officially embed an informal education strategy to catalyze a culture of sustainable material management that cut across all academic and administrative units in the School of Design at Syracuse University. To create these sustainable actions in the School of Design, a seed planting technique [22] for altering change behavior was utilized. Exercises such as generating idea-based solutions (using observations and surveys to develop and implement ideas on how to increase sustainability practices), using a holistic approach (which seeks to encourage personal and collective action) performing continued tasks, participatory engagement (students would gain something of value for correct sorting at the end of the year), a user-friendly approach (using humor in the communications and making corrections if necessary), facilitating improvements/making adjustments (responsive to incorrect sorting with new informative infographics) [22]. As the design disciplines are high-volume consumers of prototyping materials and convenience food and beverages (due to the long format studio educational approach teaching), two codesigned interventions were conceived. The first was the development of recycling and trash bin systems to effect change in how waste and recycling could be better managed in the school, and the second was a Material Exchange program where students could engage in a reuse and repurpose initiative to extend the life-cycle of commonly used prototyping materials. Using a change theory approach, research outputs were analyzed to assess whether the short-term outcomes were met, and what further investigations need to be conducted to achieve sustained longer-term impact.

\section{Materials and Methods}

The School of Design at Syracuse University is located inside a seven-story building, called the Nancy Cantor Warehouse (referred to as the Warehouse) in downtown Syracuse. The isolation from the rest of the university campus makes the school its own university sub-community. The School of Design houses approximately 450 students, faculty, and staff spread across five different design programs. Students come from all over the United States and international countries such as China, the United Kingdom, Egypt, Taiwan, and South Korea.

This research was built around the assumption that if codesign of intervention (and subsequent monitoring) was undertaken in collaboration between faculty, students, staff, and the maintenance staff, the culture of recycle, reduce, and reuse could be significantly improved (Figure 1). The logic model approach [23], which is commonly used visualization tool in the evaluation of formal educational programs (for example [24]), was utilized to map out how resources and research activities would result in measurable outputs, and initiate sustainability-centric behaviors, knowledge, and skills outcomes in the School of Design community. This experimental research used a single group design where all participants were given the same treatments. This linear ordering of the one-group pretestposttest design gives assessment of the dependent variable before and after the treatment is implemented. 


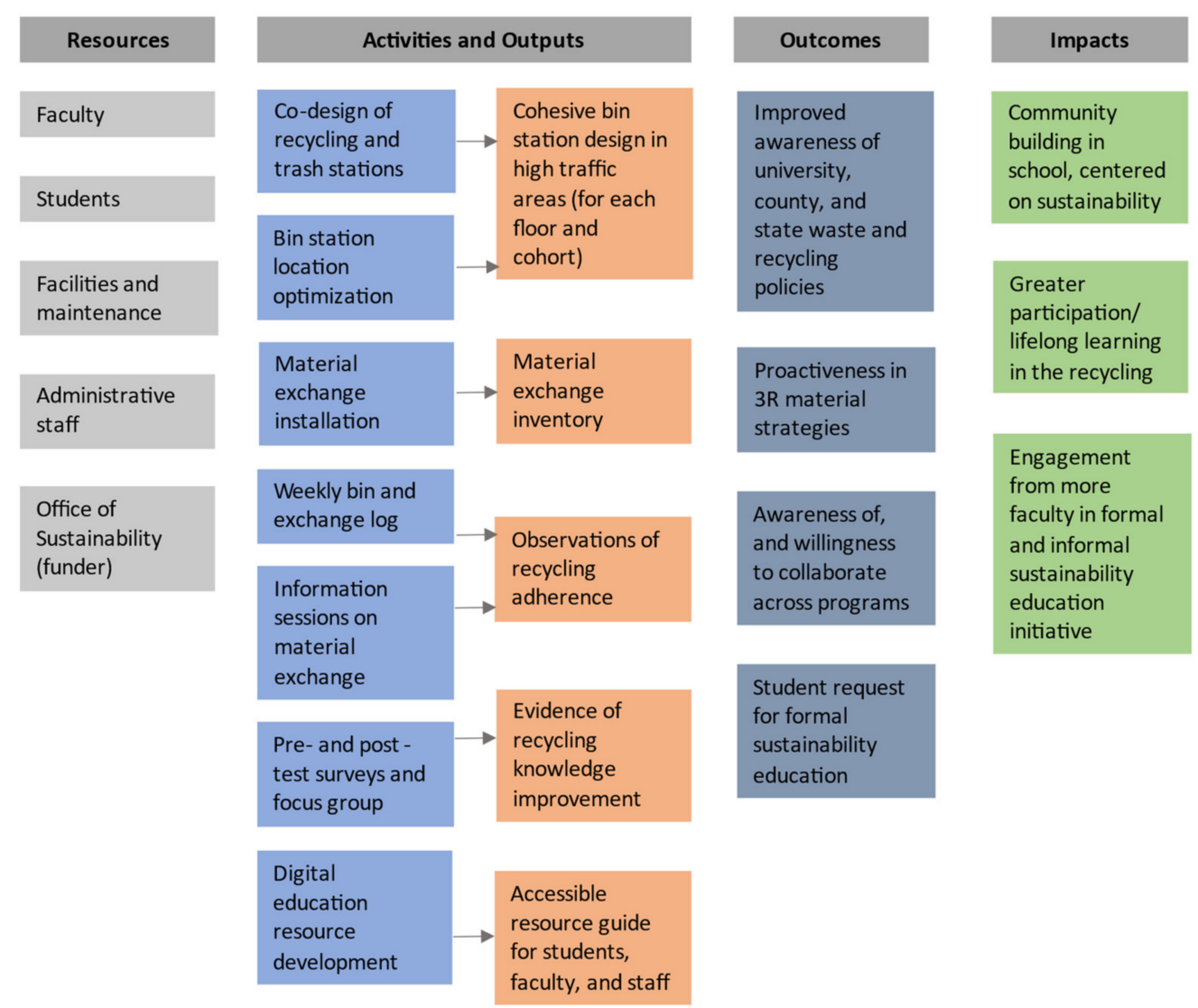

Figure 1. A Logic Model depicting the resources, activities and outputs, projected outcomes, and intended long-term impacts of the design intervention in the School of Design.

This experiment was designed to take place over the fall and spring semesters of the 2019/20 academic year. Due to the COVID-19 pandemic which caused the abrupt closure of the university during the spring semester, the research plan was interrupted. To complete data collection, the experiment was extended to the following fall semester which is shown in Table 1. At the time of the experimental installation, an online pretest survey was administered through Qualtrics to students with sophomore or higher standing in their undergraduate degree in the School of Design. Students were recruited through email and were not required to participate in both surveys. Due to the studio course configuration during the freshmen year, freshmen students were excluded from this particular study. Ten questions were included in the online survey to quantify students' perspectives and understanding of studio waste disposal, and their knowledge of whether materials can be recycled or reused (see [7] for survey design). At the end of the experiment, a posttest survey was distributed to the students. The posttest questions were the same as the pretest to measure the outcomes from the experimental design interventions on knowledge and awareness of recycling, reuse, and repurposing strategies with the school. Tableau software was used to analyze the collected data [22]. While weekly observations of students' waste disposal and recycling behaviors were monitored and recorded, this data was only used to refine the graphical messaging that formed part of the ongoing design intervention. This paper focuses on the findings from the pretest-posttest survey comparison employing two experimental design interventions: trash and recycling stations with color-coded bins and informational panels (Figure 2a-c) along with "Materials Exchange" units (Figure 3). Trash and recycling bin stations were installed across the Warehouse to reduce landfill waste. Firstly, a gray color-coded "Trash Only", an orange color-coded "Paper and Cardboard Only" bin, and a blue color-coded bin for beverage bottles and cans were placed in each station to form the three-bin system. Funds collected through the New York State $5 \notin$ bottle 
return scheme were redistributed to the students through social events. This fund recovery scheme was suspended during the COVID-19 pandemic due to health and safety concerns, thus the bottles and cans entered the non-deposit collecting recycling stream. The trash and recycling stations were monitored each week to determine where they should be placed to maximize convenience for students. Based on the observational findings of the students' waste disposal each week, informational panels were updated approximately every six weeks to provide additional recycling and waste disposal instructions in response to the observed material disposal. These graphic instructions shown in Table 2, which were codesigned by the faculty and design students, showed correct waste disposal methods for bins, and educational facts about recycling, reducing, and reusing were placed throughout the building. A total of five different versions of informational panels were created based on the students' waste disposal habits through weekly bin content observations and peer feedback.

Table 1. Timeframe of the experiment spanning from Fall 2019 through to the middle of Fall 2020. Spring 2020 had only 8 weeks of experimentation due to the school closure and experimental hiatus due to the COVID-19 pandemic. The circles indicate when design interventions (green), design observations (orange), and data collection from students (blue) took place during each 15-week semester.

\begin{tabular}{clll}
\hline & Fall 2019 & Spring 2020 & Fall 2020 \\
\hline Design intervention & $\bullet \bullet \bullet \bullet \bullet \bullet \bullet \bullet \bullet \bullet \bullet \bullet \bullet \bullet \bullet$ & $\bullet \bullet \bullet \bullet \bullet \bullet \bullet \bullet$ & $\bullet \bullet \bullet \bullet \bullet \bullet \bullet \bullet$ \\
Design observation & $\bullet \bullet \bullet \bullet \bullet \bullet \bullet \bullet \bullet \bullet \bullet \bullet \bullet \bullet \bullet$ & $\bullet \bullet \bullet \bullet \bullet \bullet \bullet \bullet$ & $\bullet \bullet \bullet \bullet \bullet \bullet \bullet \bullet$ \\
Data collection & $\bullet$ & $\bullet \bullet \bullet \bullet \bullet \bullet \bullet \bullet$ & $\bullet \bullet \bullet \bullet \bullet \bullet \bullet \bullet$ \\
\hline
\end{tabular}

(a)
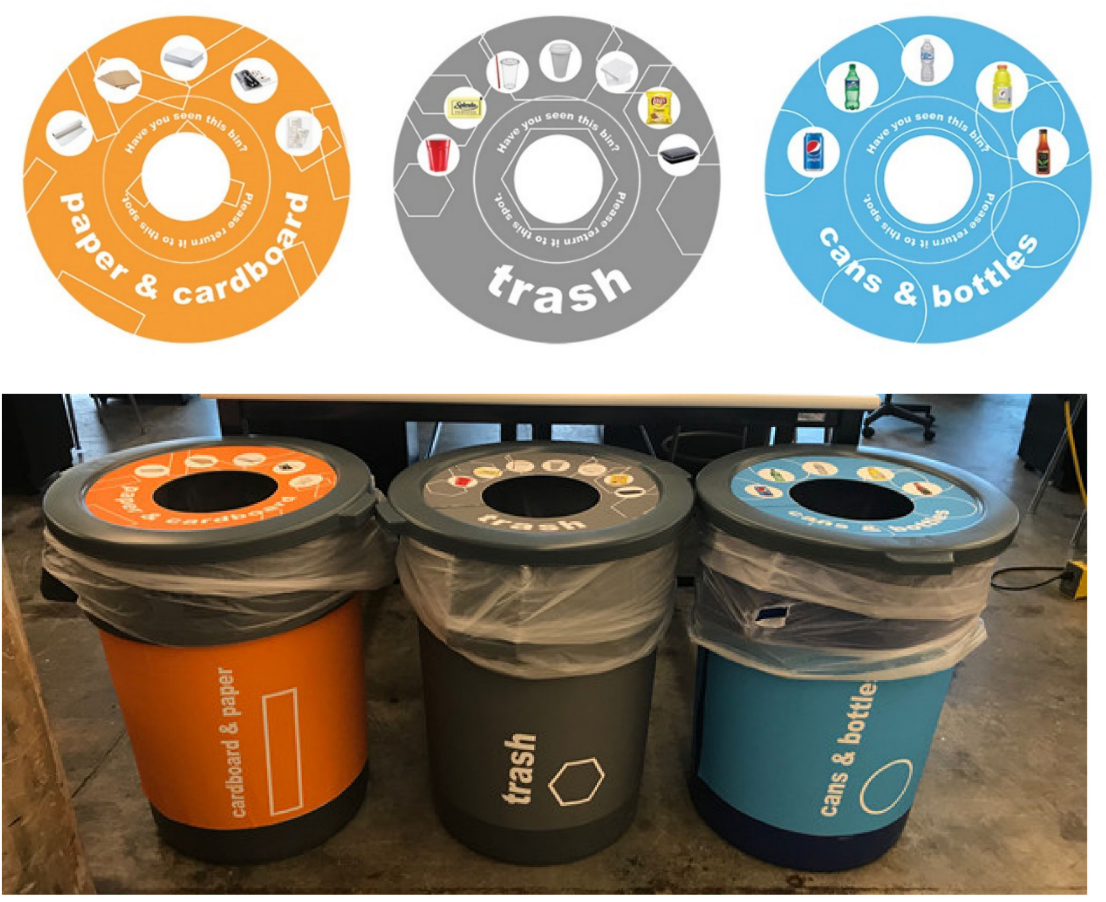

(b)

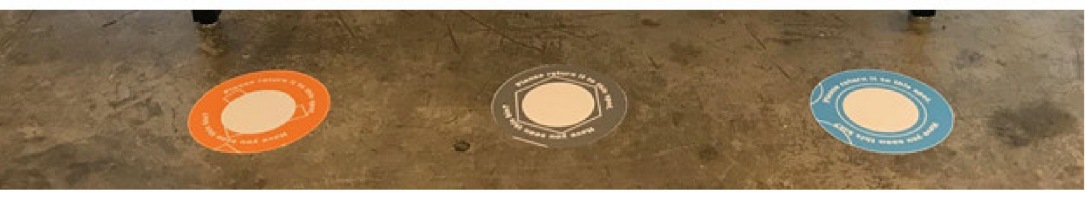

Figure 2. Codesigned trash and recycling station with color-coded bins with informational panels were installed across the building. (a) The decals that were designed and adhered to the lid of each bin; (b) The bins were wrapped with colors that matched the lids; (c) Markers on the floor to denote where the system should be placed after they were emptied by the maintenance staff. 
Table 2. Infographic design interventions which were codesigned by the faculty and students.

Design Iteration Paper and Cardboard Cans and Bottles

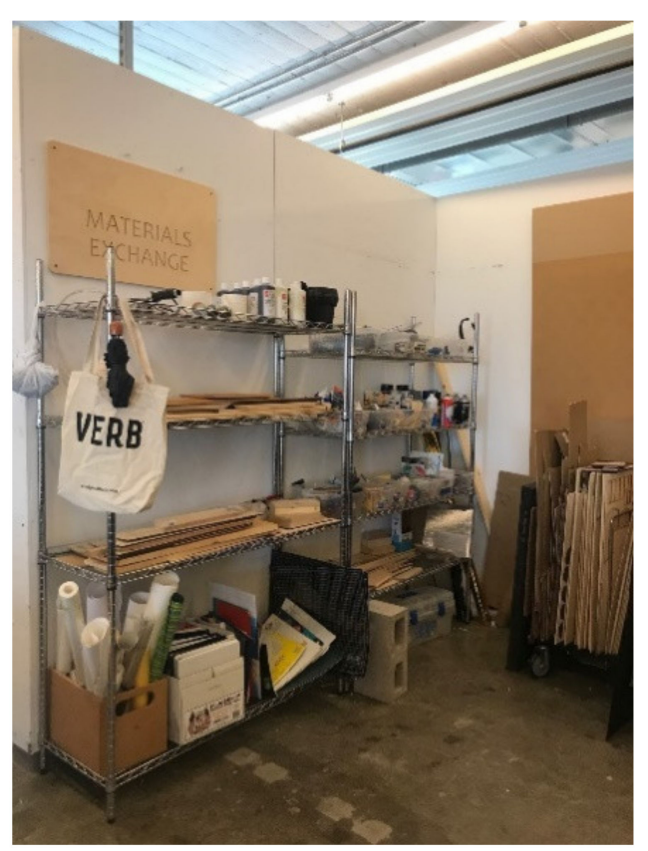

Figure 3. A typical Materials Exchange in the design studio, codesigned between students and faculty. 
In the second design intervention, "Materials Exchange" units were constructed using commercially available storage racks and containers (Figure 3). The Exchanges were installed on every floor so that students could donate, share, reuse, recycle materials and supplies from their design studio projects. Each week, materials and supplies were recorded and photographed, noting any usages or donations. Promotional graphics for taking, leaving, and collecting materials and supplies were distributed across the design floors to advertise the Material Exchange program.

In addition to the pretest and posttest survey data, a peer-led focus group was conducted to gain mid-experiment insight into whether students understood how to interact with the recycling, reuse, and repurpose-centered design interventions. The participants, who were recruited through a school-wide email, were given a true/false series of questions about what goes in the trash and recycling bin system, with open questions on their reasoning. The true/false answers were not directly analyzed, rather were used as a prompt for group discussion. The correct disposal of various beverage containers and utensils, food containers, printer paper, common prototyping materials, and conditions were discussed. The focus group was audio-recorded and coded by hand by three researchers to reveal key themes in the data [25]. An analogue affinity mapping analysis technique [26] was used to identify the key areas where student knowledge was incorrect about material end-of-life for commonly observed materials and objects.

\section{Results}

\subsection{Pretest-Posttest Comparison}

The pretest and posttest results from the experiment inferred the lack of improved waste and recycling knowledge or perspectives. Students were recruited to participate in both pretest and posttest surveys across three design programs where the treatment initiatives were employed in the School of Design. Given 60-70 students per cohort among the three design programs, the pretest and posttest surveys were distributed to approximately 180 students enrolled in the school. Students were invited to participate in both pretest and posttest across four design programs in the School of Design. A total of 67 undergraduate students $(37.2 \%)$ participated in the pretest and a total number of 60 undergraduate students (33.3\%) participated in the posttest during the 2019-2020 academic year. The questions revealed the students' growth in the fundamental waste and recyclable materials knowledge after the one academic year-long experiment of the sustainable practices utilizing the three-bin system and the Materials Exchange. The questions discovered the appropriateness of the newly developed sustainability initiative.

First, students were asked to differentiate general trash and recyclables based on the initial research of the most common waste generated in the design studio spaces. The intent for the three-bin system's waste categories and the Materials Exchange were not revealed in the questionnaires. Consistently, most students identified the aluminum cans, cardboard, paper, and plastic bottles as recyclables at both pretest and posttest. The correction rate of recycles improved slightly in the posttest.

For many common waste types in the studio spaces, students were still unclear about vinyl or plastic based items. An elaboration of "why" is discussed in the detail in the focus group discussion analysis in Section 3.2. Overall, students' responses in identifying the typical trash per Onondaga County had improved. While it is still not as significantly clear when compared to the obvious recyclables, the improvements were shown (Table 3).

Next, pretest-posttest comparison discovered that many students were confused in recognizing where the types of waste or recyclables belonged in the different colored bins. At both pretest and posttest, the gray bin for general trash seemed to be the obvious choice; however, students were similarly confused between recyclables at the administering of both pretest and posttest surveys. In the later discussion with students, the researchers discovered that there are mixed colors in the recyclables' bins in the students' housing. This has indicated that the training should go beyond the "work" space where they were spending the majority of the time but be expanded to their "living space" as well. In 
addition, the broader initiative must be made consistently throughout the campus thus reducing confusion. Once, the intent of this research was revealed in the questionnaire to inform students about correct color bins per waste and recyclable materials, students responded with the correct color bins per waste and recyclables. The posttest revealed a slightly improved response, which indicated the significance of the informal educational session that accompanied the activities.

Table 3. Pretest-Posttest Comparison in identifying general trash versus recyclables. The black arrows denote an improvement in correct identification of end-of-life (recycle or trash) between the pretest and posttest surveys.

\begin{tabular}{|c|c|c|c|c|}
\hline & & \multicolumn{3}{|c|}{ Correct Response Rate (\%) } \\
\hline & & Pretest & Posttest & Improvement \\
\hline \multirow{12}{*}{ General trash } & Acrylic plastic & 89.6 & 83.3 & \\
\hline & Chips and Popcorn Bags & 95.5 & 86.7 & \\
\hline & Cold Coffee Cups & 64.2 & 58.3 & \\
\hline & Fabrics & 67.2 & 55.0 & \\
\hline & Form/Form Core Boards & 88.1 & 91.7 & $\uparrow$ \\
\hline & Metal & 41.8 & 48.3 & $\uparrow$ \\
\hline & Paper Coffee Cups & 58.2 & 71.7 & $\uparrow$ \\
\hline & Paper Food Containers & 58.2 & 66.7 & $\uparrow$ \\
\hline & Paper Plates & 50.8 & 51.7 & $\uparrow$ \\
\hline & Plastic Food Containers/Utensils & 62.7 & 63.3 & $\uparrow$ \\
\hline & Styrofoam & 92.5 & 96.7 & $\uparrow$ \\
\hline & Wood & 50.8 & 60.0 & $\uparrow$ \\
\hline \multirow{4}{*}{ Recyclables * } & Cans & 85.1 & 86.7 & $\uparrow$ \\
\hline & Cardboard & 92.5 & 96.7 & $\uparrow$ \\
\hline & Paper & 98.5 & 98.3 & $\uparrow$ \\
\hline & Plastic Bottles & 98.5 & 98.3 & \\
\hline
\end{tabular}

* Since the building is considered institutional, the waste collection of the recyclables are cardboard and paper. The other waste types are considered general trash. However, depending on the building, aluminum cans and plastic bottles are separately collected as pursued in this research, and the maintenance crew or designated individuals or groups take them to a collection facility.

Students were then asked to identify their usage and donation frequencies of the Materials Exchange placed on each program floor. While their responses in the usage and donation frequencies did not indicate significant differences, the results did show that while monthly usage had improved among students, more students avoided utilizing the initiative by the end of the academic year. It was hypothesized by the researchers that diminished uptake could have been due to COVID-19, specifically precautionary measures of not using shared materials and supplies (Figure 4a). However, their donation rate had improved slightly indicating that the students felt more comfortable donating unused materials or supplies (Figure $4 b$ ).

Lastly, students were asked if they were interested in sharing the Materials Exchange beyond their own programs. Only $66.7 \%$ of the participants felt comfortable sharing across the entire design programs of the School of Design at the pretest. However, the posttest revealed that their willingness improved to $78.3 \%$. This demonstrated improvements in the development of a sense of community across design programs, as well as an increase in willingness to participate in the codesigned reduce, reuse, and recycle initiatives. 


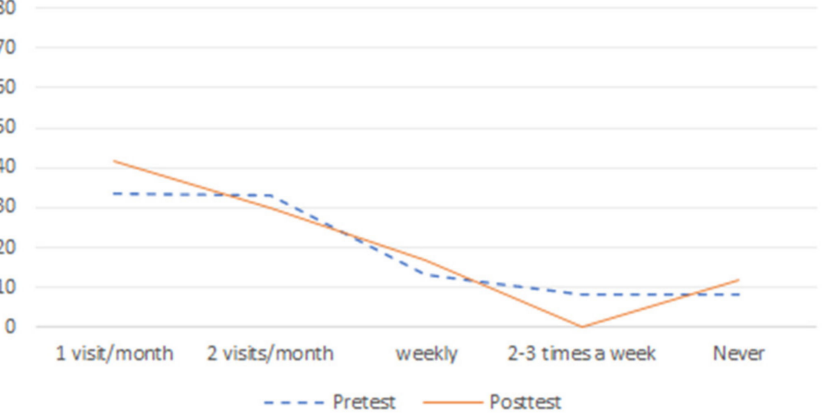

(a)

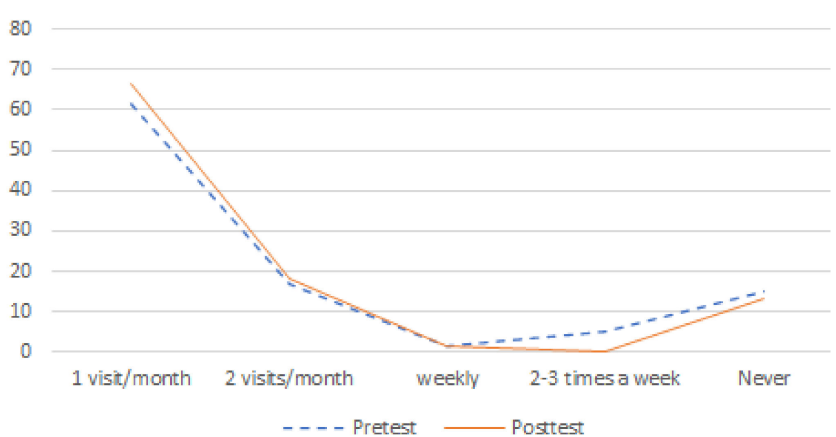

(b)

Figure 4. Pretest-posttest for the Material Exchange interaction. (a) Pretest and posttest comparison for usage frequency by percentage; (b) pretest and posttest comparison for donation frequency by percentage.

\subsection{Focus Group}

The analysis of the focus group discussions revealed that even after three design iterations of the information panels that accompanied the trash and recycling bin stations, confusion still existed around which bin certain items should be placed in. Most confusion centered on how to manage food containers and coffee cups, and what types of bottles and cans qualified as eligible for the New York State bottle deposit return program. Table 4 shows key areas in missing knowledge that emerged for each bin type. Students' suggestions and comments from the focus group discussions were incorporated in the next round of informational panels. For example, students commented that $5 \notin$ New York State bottle deposit should be clearly communicated since some bottles and cans are recyclable but not in New York State.

Students expressed that often informational panels are overlooked in the school. Due to the nature of the school, the walls are full of students' design iterations, various flyers, and graphic products. To this point, students emphasized the importance of formal education at the beginning of the semester to inform the correct waste disposal instructions. Educational videos, content shuffling through social media pages, and formal lectures were also suggested.

Table 4. Affinity mapping results showing key areas of incorrect disposal knowledge that arose concerning the correct bin designation. The asterisk denotes that more than 2 participants shared this misinformed view on recycling/trash distinction.

\begin{tabular}{ll}
\hline Bin Type & Key Themes of Incorrect Knowledge \\
\hline Paper and cardboard & $\begin{array}{l}\text { Paper drinking cups are recyclable * } \\
\text { Paper food bags are recyclable }\end{array}$ \\
\hline \multirow{3}{*}{ Bottles and cans } & $\begin{array}{l}\text { Crushed cans are deposit-return eligible } \\
\text { Label-less bottles are deposit-return eligible * } \\
\text { Bottles without return logo are deposit-return eligible * }\end{array}$ \\
\hline & Plastic food packaging is recyclable * \\
General trash & Utensil recycling is material dependent \\
& Utensils are recyclable * \\
\hline
\end{tabular}

\section{Discussion}

Improved awareness of recycling and waste. That there was an improved understanding of recycling and trash designation of common items in the studio such as paper, food containers, most beverage containers, and some prototyping materials was encouraging and consistent with the results from the pilot study [7]. The iterative process of improving the signage above the trash and recycling stations to reflect common disposal errors also 
improved the overall observations of the bin content every week. Again, consistent with other studies, positive recycling behaviors were observed with the setting up of a recycling station [27-29], incentives for recycling [30] in our case through the collective benefit of recouping $5 \not$ deposits, and informational messaging to encourage adherence [31,32].

However, there was still confusion around the limitations of the NYS bottle deposit refund scheme as illustrated in the focus group discussion. For half of the group $(n=6)$, there was the assumption that all cans and bottles are eligible. Indeed, they are all recyclable, but not all are accepted by the collection facilities. Additionally, there was the misconception that plastic food packaging was also recyclable if it had been washed, and disposed of in the recycling, rather than the trash bin. Whilst some food packaging can be rinsed and recycled in Onondaga County, single-use take-out packaging is not accepted.

Packaging is responsible for approximately one third of the world's plastic production [33] and despite social and health pressures to eschew it, total avoidance in the university commissary environment is difficult. Whilst these objects are labelled such that they indicate recyclable, placing them in the recycling receptacle contaminates the entire content, which is an unintended consequence of "overinclusive" labelling. A recent study found that overinclusive recycling is "driven by emotional aversion to trashing" [34], and we hypothesize that that could be an influencing factor in our study.

3R material strategy and collaboration across programs. In today's sustainable design, manufacturing, and fabrication, the $3 \mathrm{R}$ (reuse, reduce, and recycle) concept is transforming and evolving into the $6 R$ stages (reduce, reuse, recover, redesign, remanufacture, recycle) and further $9 \mathrm{R}(6 \mathrm{R}+$ resilience, reassessment, restructuring) optimizing its process into circular lifecycle paradigm $[35,36]$. In product design, this has expanded even further to a $10 \mathrm{R}$ model that begins with R0 "refuse" whereby designers "make a product redundant by abandoning its function or by offering the same function with a radically different product" [37]. The 10R framework could be modelled within the school with more buy-in from all design faculty. Indeed, the authors could implement these strategies within their own teaching but could not be enforced beyond those limits. By initiating a material sustainability approach centered on commonly and widely accepted $3 R$ principles, we hypothesize that it may be easier to introduce more strategies gradually.

In this present study, although impeded due to COVID-19 and cautionary measures around it, the use and donation of unused materials and supplies to the Materials Exchange were steady throughout the academic year. While it was not formally measured, students benefited from using materials and supplies available as needed and contributed to waste reduction. Moreover, installing the Materials Exchange program on each studio floor created the opportunity for students from different programs to share and exchange prototyping materials therefore building a sense of community. For example, Museums Studies students typically use less raw materials for their classes, therefore giving them access to the Material Exchange did not only build community but also enabled the reuse/repurpose of smaller pieces of materials instead of purchasing larger amounts and wasting the surplus. The premise of the Material Exchange program was to create a local internal circular economy (CE). Further experimentation is required to determine if this model could be effectively used in conjunction with other CE teaching methods [38,39], and influence deeper-thinking before beginning to source materials for studio projects.

Informal/formal education and future study for sustained impact. There are several character tendencies and learning styles that are more meaningful to students and this project was able to capitalize on those inclinations to augment behavior quicker. Today's students have been identified as the "most entrepreneurial generation", ready to mobilize for causes through which they can make a difference and improve the world according to their values [40]. Lectures and papers are less effective teaching methods for this group [41], so more user-friendly communications were added to the learning repertoire (infographics, website, and in-person sessions). Utilizing the trash and recycling system in combination with six-weekly informational poster redesigns capitalized on the student group's preferred learning methodology of experience over theory [41]. In addition to 
the infographics and informational sessions, a website was developed as an instructional tool (www.sodcares.com accessed on 30 June 2021) in order to disseminate information. The intent of this website was to (1) outline the intents and objectives of this research, (2) be used as an instructional tool to inform the three-bin system and Materials Exchange initiatives, (3) to continuously update the progress and expansion of the initiative across the university campus.

As we plan to expand the initiative through both formal and informal instruction in the "living learning" communities in the upcoming academic year, this website will be used as a mode of instruction to inform the broader student body across campus. This initiative will be strengthened further by embedding formal and informal instruction in a first-year studio course. It is planned that this implementation will occur in a freshmen seminar course, thus formally induct students in appropriate disposal habits of waste and recycling of materials per the county's guidelines. We plan to teach them to also to think beyond compliance. For example, the Material Exchange program as a local circular economy. Informal activities such as waste audits, rotating informational panels, and clear colorcoded signages at the university dormitories will continue to reinforce sustainable-mind behaviors and increase students' awareness of their environmental impacts [42]. Ultimately, our working hypothesis for this expansion is that if the recycling and trash protocols are the same at home and work, less confusion and more recycling will occur $[43,44]$.

Author Contributions: Conceptualization, L.R.M. and S.L.; methods, L.R.M. and S.L.; formal analysis, L.R.M. and S.L.; investigation, L.R.M., S.L., M.S. and R.K.; writing-original draft preparation, L.R.M. and S.L.; writing-review and editing, S.L., M.S. and R.K.; visualization, L.R.M. and S.L.; funding acquisition, L.R.M. and S.L. All authors have read and agreed to the published version of the manuscript.

Funding: This research was supported by Campus as a Laboratory in Sustainability Grant administered by the Office of Sustainability at Syracuse University.

Institutional Review Board Statement: The study was conducted according to the guidelines of the Declaration of Helsinki, and approved by the Institutional Review Board of Syracuse University (protocol code 19-268 on 9 October 2019).

Informed Consent Statement: Informed consent was obtained from all subjects involved in the study.

Data Availability Statement: The data presented in this study are available on request from the corresponding author.

Acknowledgments: Thank you to Alexandria Borrelli, Sophia Jaberi, Nicholas Ng, and Kaye Park for their diligent data collection on this project. Our thanks are also extended to Sijin Zhou for her preliminary data analysis of the survey data.

Conflicts of Interest: The authors declare no conflict of interest.

\section{References}

1. UNESCO. Education for Sustainable Development: A Roadmap; UNESCO: Paris, France, 2020; ISBN 978-92-3-100394-3.

2. Décamps, A.; Barbat, G.; Carteron, J.C.; Hands, V.; Parkes, C. Sulitest: A collaborative initiative to support and assess sustainability literacy in higher education. Int. J. Manag. Educ. 2017, 15, 138-152. Available online: https://www.researchgate.net/publication/ 317623850_Sulitest_A_collaborative_initiative_to_support_and_assess_sustainability_literacy_in_higher_education (accessed on 30 June 2021). [CrossRef]

3. Mallow, S.; Toman, I.; van't Land, H. IAU 2nd Global Survey Report on Higher Education and Research for Sustainable Development; IAU: Paris, France, 2020. Available online: https:/ / www.iau-hesd.net/documentation/4858-2nd-global-survey-report-highereducation-and-research-sustainable-development (accessed on 30 June 2021).

4. Hopkinson, P.; Hughes, P.; Layer, G. Sustainable graduates: Linking formal, informal and campus curricula to embed education for sustainable development in the student learning experience. Environ. Educ. Res. 2008, 14, 435-454. [CrossRef]

5. Müller-Christ, G.; Sterling, S.; Van Dam-Mieras, R.; Adomßent, M.; Fischer, D.; Rieckmann, M. The role of campus, curriculum, and community in higher education for sustainable development-A conference report. J. Clean. Prod. 2014, 62, 134-137. [CrossRef]

6. Winter, J.; Cotton, D. Making the hidden curriculum visible: Sustainability literacy in higher education. Environ. Educ. Res. 2012, 18, 783-796. [CrossRef] 
7. Lee, S.; Manfredi, L.R. Promoting recycling, reducing and reusing in the School of Design: A step toward improving sustainability literacy. Int. J. Sustain. High. Educ. 2021. [CrossRef]

8. Redondo, I.; Puelles, M. The connection between environmental attitude-behavior gap and other individual inconsistencies: A call for strengthening self-control. Int. Res. Geogr. Environ. Educ. 2017, 26, 107-120. [CrossRef]

9. United Nations. Report of the World Commission on Environment and Development: Our Common Futuree; United Nations: New York, NY, USA, 1987.

10. Oyelola, K.O. Design for Sustainability: A Sustainability Approach to Design Education That Helps Promote Sustainable Consumer Behavior; Carleton University: Ottawa, ON, Canada, 2012. Available online: https:/ /www.academia.edu/32426483/DESIGN_FOR_ SUSTAINABILITY_1_Design_for_Sustainability_A_Sustainability_Approach_to_Design_Education_That_Helps_Promote_ Sustainable_Consumer_Behavior (accessed on 30 June 2021).

11. Connolly, M.R.; Seymour, E. Why Theories of Change Matter; (No. WCER Working Paper No. 2015-2); 2015. Available online: https:/ / files.eric.ed.gov / fulltext/ED577054.pdf (accessed on 30 June 2021).

12. Huerta, L.A.; Zuckerman, A. An institutional theory analysis of charter schools: Addressing institutional challenges to scale. Peabody J. Educ. 2009, 84, 414-431. [CrossRef]

13. Henk, M. Change Theories in Education. We Teach We Learn. 28 January 2010. Available online: http:/ / www.weteachwelearn. org/2010/01/change-theories-in-education/ (accessed on 30 June 2021).

14. Jones, B. "Table Top Theory" as a Policy Framework for Gauging the Confluence of Teaching and Private Sector Interests. Teach Educ. Q. 2007, 34, 185-204. Available online: http:/ / www.jstor.org/stable/23479024 (accessed on 21 July 2021).

15. CleanRiver. 10 Tips for Campus Recycling Success. Available online: https://cleanriver.com/10-tips-for-campus-recycling/ (accessed on 30 June 2021).

16. Kaplowitz, M.D.; Yeboah, F.K.; Thorp, L.; Wilson, A.M. Garnering input for recycling communication strategies at a Big Ten University. Resour. Conserv. Recycl. 2009, 53, 612-623. [CrossRef]

17. UC Berkeley Sustainability and Carbon Solutions. Zero Waste. Available online: https://sustainability.berkeley.edu/zero-waste (accessed on 30 June 2021).

18. Joseph, N. Reducing Trash through Thoughtful Design. College of Arts and Sciences-University of Washington. July 2017. Available online: https: / / artsci.washington.edu/news / 2017-07/reducing-trash-through-thoughtful-design?_ga=2.246278276.14465160 27.1625063584-1025352244.1623173172 (accessed on 30 June 2021).

19. Ellen MacArthur Foundation. What Is the Circular Economy? Available online: https://www.ellenmacarthurfoundation.org/ circular-economy / what-is-the-circular-economy (accessed on 30 June 2021).

20. McDonough, W.; Braungart, M. Cradle to Cradle: Remaking the Way We Make Things; North Point Press: New York, NY, USA, 2010.

21. EPEA. Cradle to Cradle-Rethinking Products. Available online: https:/ / epea.com/en/about-us/cradle-to-cradle (accessed on 30 June 2021).

22. Gabriele, S.F. The "roundtable" for school learning and planning groups: Planting a seed for systemic renewal. In Kybernetes; Emerald Group Publishing Ltd.: Bingley, UK, 2002; Volume 31, pp. 1361-1368. Available online: https:/ /www.emerald.com/ insight/content/doi/10.1108/03684920210443563/full/html (accessed on 30 June 2021).

23. W.K. Kellogg Foundation. W.K. Kellogg Foundation Logic Model Development Guide; W.K. Kellogg Foundation: Detroit, MI, USA, 2004.

24. McLaughlin, J.A.; Jordan, G.B. Logic models: A tool for telling your program's performance story. Eval. Program Plann. 1999, 22, 65-72. [CrossRef]

25. Compton, M.; Barrett, S. A Brush with Research: Teaching Grounded Theory in the Art and Design Classroom. Univers. J. Educ. Res. 2016, 4, 335-348. [CrossRef]

26. Dam, R.F.; Siang, T.Y. Affinity Diagrams—Learn How to Cluster and Bundle Ideas and Facts. Interaction Design Foundation (IxDF). Available online: https:/ / www.interaction-design.org/literature/article/affinity-diagrams-learn-how-to-cluster-and-bundleideas-and-facts (accessed on 30 June 2021).

27. McCoy, K.; Oliver, J.J.; Borden, D.S.; Cohn, S.I. Nudging waste diversion at Western State Colorado University: Application of behavioral insights. Int. J. Sustain. High. Educ. 2018, 19, 608-621. [CrossRef]

28. O'Connor, R.T.; Lerman, D.C.; Fritz, J.N. Effects of number and location of bins on plastic recycling at a university. J. Appl. Behav. Anal. 2010, 43, 711-715. [CrossRef]

29. Ofstad, S.P.; Tobolova, M.; Nayum, A.; Klöckner, C.A. Understanding the Mechanisms behind Changing People's Recycling Behavior at Work by Applying a Comprehensive Action Determination Model. Sustainability 2017, 9, 204. [CrossRef]

30. Viscusi, W.; Huber, J.; Bell, J. Promoting recycling: Private values, social norms, and economic incentives. Am. Econ. Rev. 2011, 101, 65-70. [CrossRef]

31. Fritz, J.N.; Dupuis, D.L.; Wu, W.-L.; Neal, A.E.; Rettig, L.A.; Lastrapes, R.E. Evaluating increased effort for item disposal to improve recycling at a university. J. Appl. Behav. Anal. 2017, 50, 825-829. [CrossRef] [PubMed]

32. Miller, N.; Meindl, J.N. The Effects of Bin Proximity and Visual Prompts on Recycling in a University. Behav. Soc. Issues 2016, 25. [CrossRef]

33. PlasticsEurope. Plastics - The Facts 2016. An Analysis of European Plastics Production, Demand and Waste Data; PlasticsEurope: Brussels, Belgium, 2017. Available online: https:/ / www.plasticseurope.org/application/files/4315/1310/4805/plastic-the-fact2016.pdf (accessed on 30 June 2021). 
34. Catlin, J.R.; Leonhardt, J.M.; Wang, Y.; Manuel, R.J. Landfill or Recycle? Pro-Environmental Receptacle Labeling Increases Recycling Contamination. J. Consum. Psychol. 2021, jcpy.1216. [CrossRef]

35. Jayal, A.; Badurdeen, F.; Dillon, O. Sustainable manufacturing: Modeling and optimization challenges at the product, process and system levels. CIRP J. 2010, 2, 144-152. [CrossRef]

36. Acciona \#LearnSustainability: The 3Rs, 6Rs and 9Rs. Available online: https://www.activesustainability.com/sustainable-life/ learnsustainability-the-3rs-6rs-and-9rs / (accessed on 21 July 2021).

37. Potting, J.; Hekkert, M.; Worrell, E.; Hanemaaijer, A. Circular Economy: Measuring Innovation in the Product Chain; PBL Publishers: Novato, CA, USA, 2017.

38. Whalen, K.A.; Berlin, C.; Ekberg, J.; Barletta, I.; Hammersberg, P. 'All they do is win': Lessons learned from use of a serious game for Circular Economy education. Resour. Conserv. Recycl. 2018, 135, 335-345. [CrossRef]

39. Kirchherr, J.; Piscicelli, L. Towards an Education for the Circular Economy (ECE): Five Teaching Principles and a Case Study. Resour. Conserv. Recycl. 2019, 150, 104406. [CrossRef]

40. Francis, T.; Hoefel, F.; McKinsey. Generation Z Characteristics and Its Implications for Companies. Available online: https://www.mckinsey.com/industries/consumer-packaged-goods/our-insights/true-gen-generation-z-and-itsimplications-for-companies (accessed on 30 June 2021).

41. Nicholas, A. Preferred Learning Methods of Generation Z. In Proceedings of the Northeast Business and Economics Association 46th Annual Conference, Newport, RI, USA, 7-9 November 2019.

42. Cheung, T.Y.; Fok, L.; Cheang, C.C.; Yeung, C.H.; So, W.M.W.; Chow, C.F. University halls plastics recycling: A blended intervention study. Int. J. Sustain. High. Educ. 2018, 19, 1038-1052. [CrossRef]

43. McDonald, S.; Oke, A. Recycling at home and work: An exploratory comparison. Soc. Bus. 2018, 8, 145-165. [CrossRef]

44. McDonald, S. Green behaviour: Difference in recycling behaviour between the home and the workplace. In Going Green: The Psychology of Sustainability in the Workplace; Bartlett, D., Ed.; The British Psychological Society: Leicester, UK, 2011; Volume 7, pp. 59-64. Available online: https://rgu-repository.worktribe.com/output/248770/green-behaviour-difference-in-recyclingbehaviour-between-the-home-and-the-workplace (accessed on 30 June 2021). 